Library Acquisitions: Practice \& Theory, 1992, Vol. 16 No. 2, p. 93-102.

ISSN: 0364-6408

http://www.sciencedirect.com/science/journal/03646408

http://dx.doi.org/10.1016/0364-6408(92)90074-3

(C) 1992 Pergamon Press Ltd.

\title{
AN INTERVIEW WITH RICHARD R. ROWE, PRESIDENT AND CEO, THE FAXON COMPANY
}

\author{
Interviewed by Carol Pitts Hawks, Editor-in-Chief and Adrian W. Alexander, \\ Member, Editorial Board
}

\section{RICHARD R. ROWE}

\begin{abstract}
This interview was conducted at the American Library Association Annual Conference in Atlanta, GA, on July 2, 1991. Richard R. Rowe candidly comments on issues such as recent ventures announced by his company, The Faxon Company, scholarly publishing and intellectual communities; and skills for librarians.
\end{abstract}

Dr. Rowe met with Carol Pitts Hawks and Adrian W. Alexander on July 2, 1991, at the American Library Association Annual Conference in Atlanta, GA. The discussion that took place follows.

LAPT: Word is reaching libraries about Faxon's new endeavor, Faxon Research Services (FRS), and the hiring of Tom Michalak to head that service. Can you tell us more about your plans for that service?

Rowe: We've been looking at the issue of document delivery and table of contents indexes for some time. It's been clear from the user's point of view and from the librarian's point of view that a lot of money is spent on journals when, in fact, the users find it very difficult to know what is in those journals. So, one of our first goals is to establish some tools that would enable knowledge workers, scholars, and researchers to have more ready access to the material that libraries are already buying. Then it became clear that, particularly with the development of new technologies such as the fax machine, there is now the ability to deliver on-demand material to end users directly or through libraries and that there is in fact a growing desire on the part of researchers and other users of libraries to have access to individual items when they want them. So, we've talked about the library subscription business, which remains our core business, as a "just in case" business where libraries quite correctly and appropriately buy material and have comprehensive archives that are there in case someone wants and needs them. This means something that will last for a long time; this means completeness, and it means that one can, with a high degree of reliability, trust that the item, old or new, that one wants is there in the library.

The "just in time" business, which we call FRS, is much more of a consumable item. It will, by and large, not be archived. It will in no way replace the requirement and need for a library to have a comprehensive, long-term, and in-depth archive of materials. The service will serve individual researchers' needs both for things that the library doesn't have that they need, but also in 
some cases, for things the library does have. For those items, it may just be cheaper to deliver that article via FRS to the end user in the chemistry lab or the graduate student in the dormitory than to retrieve the item from the shelf, make a copy, make the royalty payment and so forth. FRS will handle all the royalty payments. FRS will handle the delivery to the end user, if the library wants us to do that. The cost, I think, will be quite modest. A lot cheaper than the library having to do it themselves. So, we see FRS as a service designed to facilitate access to the content of material itself and to do that quickly and inexpensively in a way that is complimentary to, rather than as a substitution for, the current library subscription holdings.

LAPT: Obviously, there are other competitors already in this field. What do you think Faxon's approach brings differently to this product?

Rowe: Well, one of the areas that is most sensitive in this whole area is the relationship with publishers. Publishers are very concerned about the way technology is affecting their enterprise. They are trying to understand how they can continue to have thriving enterprises that will take into account the new technologies that are emerging. There are organizations that are providing document delivery services and index services. There are many more that are narrow in their scope or that provide a subset. Our approach has been to try to have a comprehensive list. Initially, we are aiming at the 10,000 titles most frequently ordered through Faxon. We figured that the ones that our clients want are the index of the titles that they are buying. We are also adding additional titles when groups request them. For instance, in our discussions with the Medical Library Association, they have identified 2,700 key titles for the medical profession. They want to make sure that FRS has all of those. Whether or not those are part of our original 10,000, we will make sure that we have that subset available in the index. But I think, one of the real strengths of Faxon is that we have close relationships with publishers and are working closely with them in working out ways to deliver this material in a more cost-effective way.

LAPT: In that same vein, in a recent Boston Globe interview, you indicated that in five years 50\% of your business might be serials subscriptions and 50\% might be document delivery. Is that an accurate reflection of your statement?

Rowe: Let me say this about the Globe article, I was very often misquoted. I felt very unhappy about that article. But, we know there is an enormous amount of photocopying of articles being done now. Most of it generates no royalties for the publisher. One of our goals is to offer a service that is easy enough to use, that is cheap enough to use, that in fact, people will as a matter of convenience use. We have commercial clients who are currently copying 10,000-15,000 documents a month. That's a lot. If our estimates are correct, we think that there will be an enormous amount of this individual document delivery. Now, my own sense is that document delivery of the sort that FRS is providing is very much an intermediary process. In the longer term, and I hope that it won't be too long, I think publishers will begin selling their journals in electro-subscription format - actually releasing the articles at the time that the editor says the article is ready to go. There is no need for them to come through the periodical process that we now have like the July issue and the August issue. Instead, when the article is ready it is released and distributed electronically to the subscriber of that journal. I don't think that it is a sane strategy over time for libraries, for readers, or for publishers to move to individual purchase of individual documents. It's not a good way for the information systems to evolve. It puts too much pressure on 
writing stuff that will have an immediate demand. In fact, purchase on an item by item basis will tend to drive out material that should be available in the knowledge base but may not at the moment be popular. One of the things I fear is a kind of "keyword of the month" club where everyone will be writing the article that will have the right keywords in it so that someone will retrieve it and buy it. That kind of reactivity to the technology and to the change in the system would be a tragedy. So I am hoping that the document delivery portion of FRS will have a short life in the sense that it will be replaced by a more comprehensive electro-subscription service. It is clear, however, that even with lots of what I call electro-subscriptions, there will be lots of individual documents that people will need. They don't have a subscription to that particular title and the technology will enable us to scan many, many more titles and find things that we otherwise simply wouldn't know about that don't happen to be in our own collections at the moment. So, we see this as a major enterprise but not one that will replace the subscription business. I think the paper subscription will over time be converted to the electro-subscription.

LAPT: Given your traditional role with the paper subscriptions, what would your role be with the electro-subscriptions?

Rowe: Subscription agent as always before. Some publishers will want us to be the actual distributors of their material electronically. Other publishers will be quite content to have us forward the orders to them. What I say at Faxon is that we ought to be actively figuring out how to make our current services obsolete. Because if we don't, someone else will. I'd much rather be the one to replace our current services. What we know is that information technology is changing everything about the information business very rapidly. Those that try to hold on to the past, those that focus on the product rather than the service, are dead. They just won't survive.

LAPT: In this environment, do you think that the refereeing process is going to survive as it is today?

Rowe: I've said that the twenty-first century will be the Century of the Mind. It seems to me that the priestly functions of the Century of the Mind have to do with what we call the core publishing functions. They are absolutely essential. They are not going to go away. They are going to be more important rather than less important. And those priestly functions are to solicit, to select, to refine, and to promote. Those four functions are going to become increasingly important because we haven't seen anything yet in terms of the quantity of information. There are going to be more authors, more publishers, and more readers. We're in the dark ages as compared with how things will be in the next century in terms of the use and recognized value of information.

LAPT: But, isn't the overload of information already there?

Rowe: But that just creates a wonderful opportunity for people like librarians and Faxon to say what are the problems that these changes bring. Richard Saul Wurman is an architect who wrote a book called Information Anxiety. He talks a lot about the whole issue of the information overload and the guilt that people experience from not keeping up with their reading. We did a survey of readers and one of the things we found was that $20 \%$ (these are actual active researchers) said that they read less than $10 \%$ of what they should read. One in five reads less than $10 \%$ of what they should read. Two-thirds of the sample reported that they read well under half of what they should. 
Now, what does that say? That's a tremendous opportunity for someone to relieve that sense of guilt. Now, how do you do it? That's another question. But, there is a need there in terms of people who are going around with a black cloud over their head. So, these changes and this information overload brings tremendous opportunities particularly for people who are managers of information like librarians. It's an incredible opportunity. The question is who will take up those opportunities.

LAPT: What kind of skills do you think librarians need to pursue these opportunities? Do we lack the skills or is it simply a failure to take the initiative?

Rowe: I've been asked to serve as a member of the Industrial Advisory Committee of the ALA President, Pat Schuman. Pat and Richard Dougherty asked us to meet with them and to help them think through from our perspectives from being in business how we might help ALA as an organization and how we might help librarians as a profession. There was some suggestion in that meeting that businesses could be sources of funds to help replace declining government funds. I said that there is no way that businesses can replace declining government funds. However, Pat Schuman really made it clear that they were asking for our ideas and not our money. I suggested that the biggest missing piece in librarians today is marketing skills. Maybe what we need is an institute program that will help librarians learn how to be more effective marketers because we have such a tremendous thing to sell. Many of us in the library and information field are still very hesitant about the idea of marketing or selling. Somehow libraries should just sell themselves because they are so good. Why should we have to use any of these dirty tricks of Madison Avenue to get people to use our services? But, the fact of the matter is that there are principles of marketing that do make a difference. Getting resources is a major problem today for libraries of all kinds - public, academic, corporate.

I made a second, more radical suggestion-let's have two graduate level courses in marketing as a requirement for the MLS degree. Let's go to the accreditation committee and put two courses in for anyone who is going to be in an administrative role. I'm not sure how it would work, but let's build that in. I think that the corporate sector would be willing to put resources into such professional development. This is a long-term thing - not a short-term thing. If ALA and librarians are serious about getting more resources, I'm sure that the private sector would help in that effort. We can find 50 companies each of which will be willing to put in $\$ 10,000$ a year for five years - that's $\$ 2.5$ million. You get 20,000 librarians each to contribute $\$ 25$ a year and you've got another $\$ 2.5$ million. Not bad. And with that fund over a five-year period, you could really transform the skill level of librarians with a lot of in-service training programs, institutes for existing librarians. Build it into the training program for the degree and you could transform this field and make it something really exciting. You could draw people in and be able to generate money. The private sector would be happy to do that. It would be in our business interest too if librarians were more effective marketers. So everyone would win.

Part of what has to happen is to redefine the profession so that these high value functions that librarians do are seen as being of high value, are presented as that, and get the resources to do it well. But, that starts back at home. Saying what is a librarian, what are the skills librarians need and how do they get those skills? So, I'm willing to help make that happen but we have to hear from librarians that they want to make that happen as well.

LAPT: The two-pronged option you are talking about means you have to start educating new graduates into that as a fundamental part of the philosophy of librarianship. You have to get that 
group of graduates as they enter the profession. That does bring me to the Faxon Institute. From the most recent press release about the appointment of a Chief Operating Officer to handle day-to-day operations, you indicated that you will be devoting more attention on the Faxon Institute. From what we've heard about its first, very successful conference, I'd like to know what your plans are for the next institute.

Rowe: Our plans are very exciting. We were just delighted with the first conference. It was on scholarly communication and we decided to use some innovative methods of scholarly communication so we would be practicing what we would be preaching and not just talking about it in the old way. We had an eight-week-long electronic conference. We had over 400 written contributions to that conference discussion. It was really very positive. We learned a lot just from the process of doing it. It greatly enriched the three-day assembly we had in Reston, VA when we actually had people physically together for three days. For a lot of us we really had an eight-week conversation not a three-day one. That was really good. It was the first time we've done it so there were a lot of things we learned about how to do that kind of thing. At the conference we reported on a nationwide survey that we conducted on knowledge workers. We interviewed over 600 people who maintained a diary of work-related information acquisition. That study was very interesting. We got very positive feedback from the entire process.

Three things are going to happen as follow-up. We are in the process of preparing a synopsis of the eight-week conference in hypertext so that one will be able to search by topic and read the linkages across the conference. It will be sold on disk and there will also be a paper version. We're encouraging people to use the hypertext version of it. Again, the whole point of the Institute is to really push the envelope or to stretch our thinking about scholarly communication. One of my longstanding concerns about the library profession is that we have spent far too little time and energy analyzing our users. Faxon likes to say that we are client-driven, and our clients are librarians and so we spend a fair amount of time trying to understand librarians. But, in fact, far too little time is spent trying to understand the clients of our clients. So, the Institute is designed to focus on the clients of our clients, not on librarians and publishers, but on knowledge workers and to understand scholarly communication as related to those clients. That's the basic purpose of the Institute and we plan to continue research in that area. So one of the outcomes of this conference will be this hypertext synopsis of the conversation and content of the conference as a whole.

The second thing is that we've had several requests from individuals who want follow-up electronic conferences around particular topics. So we have considered and are beginning discussions with a couple of library schools about offering courses using the electronic conferencing tool so that people could actually take a semester-long course with a faculty member, paid tuition, and get continuing education credit for that course. One course that people have asked for is how do you create and maintain an electronic journal. Our thought was to identify a couple of people who are publishing electronic journals as faculty, get a university to give course credit for the course for a semester, and sign up 15-20 people for the course. Reading materials, critiquing papers, et cetera, can be done very nicely electronically with possibly an occasional telephone conference. So that's one thing, and we're looking at two or three courses that people have asked us to develop.

Another is a course to help librarians working in basic science, high-tech institutions. One group has indicated that we just don't have enough librarians who know how to work with scientists in this particular environment. They'd like our help in developing an institute to help people learn what electronic tools are available and how do you serve basic research scientists in 
that setting more effectively. So here's a tool that could be used without bringing people together in one place at great expense. So that's a second outcome.

A third outcome is the topic of the conference for April 1992 which will be cyber-nauticsnavigating through a world of electronic information. The topic is "Listening to the Users: Case Studies in Building Electronic Communities." The focus will be on looking at case studies of knowledge-based communities, Michael Schrage from the Los Angeles Times, who was the keynote this year, pointed out that all of this electronic networking is at base in support of intellectual communities. It isn't individuals who are being served but a group of people who are in a common intellectual search. If you think about this as supporting communities of scholars as distinct from individual scholars, then it changes your way of thinking about what you are doing. I found that a very powerful contribution to my thinking. This year's conference will be on the ways that one can navigate between and within knowledge-based communities. What are the communities? What kinds of supports do they need? How do you get from one to another, the membership of them, et cetera. And, we'll have people who will actually show some of the navigational tools that are being developed as well as talk about some of the public policy issues that are related to that.

Finally, Faxon will be announcing in 1992 a series of new guides to new electronic intellectual communities. They will be organized around the concept of knowledge based communities. Richard Wurman is on our advisory committee and will be the primary designer of those guides so that they will be real access guides. Our concept is to develop something akin to the triple A so that it will be not just a series of maps but in fact navigational services. These guides will be set up as a series and run as a profit-making enterprise; the profits for which will all go to the Faxon Institute. These will be a source of revenue for the Institute and all the profits will go back into the scholarly research area.

LAPT: Tell me a little more about what you mean by an intellectual community.

Rowe: I can give you some examples - those people working on the Human Genome Project constitute a worldwide intellectual community. The AIDS research community is another knowledge-based community. Cold fusion is another popular one. But also, the group of feminist literary critics that are trying to rewrite Freud. They constitute a community that is struggling on a worldwide basis to redefine an area of literature. Those are all communities. They are not the institutions that pay them and they are often not even the societies that they join in order to have a professional setting. There is a group of mathematicians that are working on theoretical models of queuing theory. They are literally faxing stuff around to each other all over the world. That's what I mean by knowledge-based communities.

LAPT: To take an entirely different vein, we're very interested in what is happening in the Soviet situation. You have an office there now. Can you tell me a bit more about your plans for that operation?

Rowe: We have frequent flights from Moscow to the States bringing Soviet literature, including daily newspapers from the regional republics. We have been for some time the acquisitions agent for the Library of Congress. We are also flying in several thousand U.S. consumer magazines. We've had a lot of growth in the export of Soviet material to the States and Europe. That is something that the Soviets are very eager to do more of. It's not easy. The traditional distribution 
mechanisms in the Soviet Union were all organized around Mezhdunarodnaia Kniga (MK) and that has essentially broken down. The reason it has broken down is that central government is no longer giving them hard currency. What hard currency there is is increasingly going to the institutions and they don't want to use MK as their mechanism for purchase. On the publishers' side, it's fascinating. Publishers have had absolutely no idea of what their business relationships, including sales price, were. They had no idea what happened to the material once it left their offices. So they are starting essentially from scratch, and we are now developing agreements with the publishers directly to export their materials.

LAPT: So is that route for acquiring Soviet materials through Faxon generally available to all clients?

Rowe: Yes. In a few weeks well be starting to fax newspaper material across on a newspaper-sized fax machine. Of course, we are also selling a lot of Western journals that they are buying for hard currency. We are doing a lot of our traditional subscription services there as well. Paper is still a big problem. They just don't have the paper and what they have is of poor quality. They also don't have any market mechanisms. A government agency decides how many copies of a given journal will be published and that's it.

LAPT: At ALA Midwinter 1991, you indicated that the Quality Improvement Program within the Faxon Company was the number-one priority for the 1990s. I have also heard you refer to the "just in case, just in time" and "best practice" theories. I'm very interested in what that is going to mean in your traditional operations.

Rowe: Quality improvement of our core subscription service is by far our highest priority at this point. It seems like FRS, the Institute, and the Soviet program get a lot of visibility and press but if you look at where we are investing our resources and where we're paying attention, it's in the area of improving the operational side of our core subscription services. We've introduced at this conference Faxon Manager which is the first look at one part of the upgrade that we're working on. It gives you a sense of the look and feel of the screens and the interactive nature of it. That kind of enhancement is going to continue over the next several years with no big bang but with a series of enhancements that will lead to greater accuracy, greater speed, more responsiveness, more customizability of the system. Mass customization is clearly our goal; also to become increasingly invisible so that we get out of the way between the publisher and the library. We facilitate those connections but we don't stand in the way and we aren't obtrusive in that relationship. I've argued for transparency or invisibility for a long time. Not everyone is instantly comfortable with that concept because again it sounds like if you're totally invisible, who needs you? But, again my sense is that one of the things that both librarians and publishers tell us regularly is that they don't like people in the middle. And Faxon is a "people in the middle." So we've got to get out of the middle. Because if we don't do it, someone else will. And so, getting ourselves out of the middle, disintermediating ourselves if you will, is one of our big goals.

So what does that mean in practical terms? That means that you in your library will have the experience of dealing directly with any publisher you want to deal with and getting immediate responses and performing whatever transactions you want in a way that is comfortable and easy for you. We'll be as transparent as the telephone company is when you make a telephone call. 
LAPT: But what if a library doesn't want Faxon to be transparent? I'm thinking in terms of the consolidation of effort for libraries which is why we use a middleman.

Rowe: All of those benefits have to remain and in fact, get better. It's not like we disappear in the sense that we're not there. There are different kinds of transparency obviously. I'm not saying that we won't be there. We'll be very much there but we won't be perceived as a barrier. Now, for example, here are 15 issues which need to be claimed. Our approach to that is that we want you to have zero claims. We don't want you to claim any issues. So, how do we get you to the point that you never have to claim anything? We eliminate claiming as something you have to do. Now that's the kind of transparency I'm talking about. If you eliminate all claiming because you got everything you were supposed to get, then that disappears as something you have to do. So one of our goals is how to have zero claiming. We have some pretty interesting ideas on that.

LAPT: I visited the Faxon Fulfillment Center in Ann Arbor last fall. I would be very interested in your perceptions of that facility and its role in this zero claiming scenario?

Rowe: Well, you know how we got there? We got there because of continuations. We were trying to drop ship continuations and it didn't work. It worked in a sense, but continuations have forever been a sore point, an embarrassment for us. We just haven't done it well enough. So we finally said, the only way to do continuations better is if we actually see the publication itself and physically ship it to you. Then we know when you have it because it has gone through our hands. Because of the aperiodic nature of these things, you cannot rely upon them. You may claim or not claim; you often don't know if you got it or whether you should have gotten it. So drop ship was simply an inappropriate method for continuations. There are some exceptions to that, but very few.

Normally, at Faxon we never see the product, but here is where we break the rule because the rule doesn't work well in this case. So we said we need a materials handling site. We decided that Ann Arbor would be a good site. The question then is how much further do we go. In an experiment with Springer, we have negotiated to automatically receive copies of each issue beyond the subscriptions we supply. In return, we guarantee to Springer that we will not claim issues from them but will supply customer claims from our stock. When the issues are delivered to your library, we get a UPS receipt with your signature on it, which makes it kind of hard for you to claim it. The question is whether that is a model we could further expand. UPS is already arriving at your door. How many more things can we put in that package? How often can we have it come? Does that UPS shipment have to go through Ann Arbor, or could they pick it up in Heidelberg? Do we in fact need to see the material in Ann Arbor, or does it need to have been seen and logged into a system with some barcode and logged out when received? All that logic is driven by our increasing preoccupation with quality. How do we eliminate the errors? How do we speed up the process and do it better? Frankly, it is really exciting. First because it draws on the wisdom of the people in the company at the grass roots who are actually on the front lines doing the work. They feel real good because they're making changes in the system. They're no longer pawns; they're actually running the thing. That's good for them. Their spirits go up and they feel proud about improving the quality. It's great stuff in terms of the morale in the company. So you're going to see more and more of that, and it's going to be noticeable.

What we find when people automate their claiming process, they suddenly discover all the things that they didn't get that they never knew they weren't getting. So the claiming rate goes up, just because they are doing a better job. There are some fulfillment services that throw the claims 
away. So, they don't care if you send one claim or nine, they do the same thing with all of them! Our obligation is to eliminate the problem for you. We're not going to be satisfied until you have no claims. The other good thing about the Springer experiment is that we positively deliver every item. Once we have a truck coming to your door, we might as well put it all in there. If we can use a tracking system, why not do it right?

LAPT: I have to ask the obligatory question about all the current serials cancellation projects and the effect that has on your company particularly if that trend continues?

Rowe: Well, there's going to be more and more information, more sources, more users. It will be perceived to be of higher and higher value. Well get into the habit of being informed rather than the habit of being uninformed. Today we are in the habit of being uninformed. We think being uninformed is the norm. Not knowing is the norm. That's going to change. We're going to get into the habit of knowing. And, that's going to mean that we are in the biggest boom that we've ever seen. So, I'm not worried. If we thought we were in the paper journal subscription business, we would be in deep trouble. But, I always use my ice company story. Some people talk about railroads, I talk about the ice company. Cambridge Ice Company actually built the railroad that created the town that I live in. It was a train stop. They built the railroad down to the harbor to ship their ice out. They had money, profits, market, free ice. It was terrific. The only problem was they thought they were in the ice business. They did wonderful things with ice. But, they don't exist anymore. It was purely a question of their vision. They had a vision that had no legs. They had a vision that was tied to their product and not to the value they were providing to their clients. That's the biggest danger for libraries and people in the book business. If they think that they're in the journal or book business, they're in deep, deep trouble. But, if they understand that they are at the crest of the biggest explosion and the most exciting evolution that has existed for humankind in history. It can only be great. You hang loose, take a few risks, and then enjoy it.

For every action there is a reaction. So, if there are fewer journals, what are the problems that creates? And what opportunities do those problems create for Faxon? How can we help respond to that change in a way that will lead to better access, more comprehensive access on a global basis, better connections. We'll be very busy.

LAPT: What are you proudest of about Faxon and what it has achieved and where it is going?

Rowe: What I'm proudest about at Faxon is that we have begun to create a team of people who are committed to serving the needs of scholars throughout the world. People who have become invested in the mission of the company and who feel proud of being there, who have fun working there, and who want to stay. I'm proudest of the things that I've done to help make Faxon a place that I can be proud to work in. That's what I'm proudest of. We invest a lot in people-people are at the top of our list, both our clients and our employees.

Our sabbatical program is one of the things our people like. Recently one employee indicated that he had decided he was working too hard and wanted to go to a three-day week. So we talked about it and we figured out how to make that happen. I then commented that he had just recently come back from his sabbatical, and whether that had anything to do with his decision. He indicated that indeed it did. He said that I might want to change the sabbatical program. And I said no, actually I don't. It's kind of a confirmation of the sabbatical program. The last thing we want is people working harder than they want to work or working where they don't want to work. The 
sabbatical helps you back up and say, "is this really what I want to do? Is this how I want to spend my life?" If we lose a few people along the way, that's fine. That's better for them and better for us. The sabbatical program is for everyone - the janitor gets a sabbatical. It's interesting that people will come back and they'll talk about what they've done. It's a major thing for them. Our only expectation for them during that time period is that they cannot work at Faxon. They can do anything else they want to do. Everyone is eligible for a sabbatical at the end of each seven-year period. The other wonderful thing about the sabbatical is that someone else does your job for two months. It gives someone else a chance to take more responsibility and do that job for more than a couple of weeks. That just creates more depth and more cross-training.

All the Faxon managers have to take at least one week a year of formal training at company expense away from the office. Conferences don't count. If they don't do that, they don't get a bonus and they don't get a salary increase. The bonus is postponed until they meet that requirement. And, it's cumulative, so that if you are six months behind, then you still have another one to do right away. When we first started that, people had difficulty breaking away for the training so we put the incentive in place.

LAPT: I also understand that there is a Faxon award for sticking your neck out?

Rowe: The giraffe award. In fact, the giraffe is also given to the winners of the Hugh Atkinson award at ALA. The giraffe award is for risk-taking. It need not be a successful risk but it needs to have been a significant risk. Of course, we like the risks that pay off. The message that is really important is that it's OK to take risks and that they don't all have to succeed. We've actually had fun thinking up these things to make the work conditions better.

It's an exciting time. I feel so fortunate to be in a position to help lead an organization that is trying to really contribute. I feel really fortunate personally to be doing what I'm doing. 